\title{
Assessment of Nurses' Performance Regarding Care Of Chest Trauma Patients at Trauma Emergency Unit
}

\author{
Mohammed M AL-gabri', Mona A Mohammed ${ }^{2}$ \& Mogedda M Mehany ${ }^{3}$. \\ 1. Lecture of Critical Care Nursing ,Faculty of Medicine and Health Sciences, Thamar University, Egypt. \\ 2. Assistant Professor of Critical Care Nursing Department, Faculty of Nursing, Assiut University, Egypt. \\ 3. Assistant Professor of Critical Care Nursing Department, Faculty of Nursing, Assiut University, Egypt.
}

\begin{abstract}
Background: The nurse is involved with the care of the trauma patient from arrival in the emergency department to follow-up in the trauma clinic. Chest injuries can be penetrating or the blunt type, depending on the nature and severity of the causative impact. The aim of this study was to assess nurses' performance regarding care of Chest Trauma patients at Trauma Emergency Unit. Design: Descriptive research designs were utilized in this study. Setting: This study was carried out in the emergency trauma unit at an assuit university hospital. A sample: of this study were all available nurses working in the emergency trauma unit at assuit university hospital (40). (Tools) two main tools used in this study Tool I: - (Nurses Knowledge Questioner)). Tool II: (Nurses Practice observation checklist ) Results: the result revealed Level of nurses Knowledge regards total score that the majority of the nurses $(70 \%)$ had an unsatisfactory Level total scores about chest trauma. The present study also revealed Nurses practice about chest trauma; that the majority of the nurses $(95 \%)$ had an unsatisfactory. Level total scores about chest trauma. There was no a ststistical significant difference between nurses' Knowledge and practice. The Conclusion the majority of the nurses was having an unsatisfactory level regarding nurses' knowledge and practice. There was no a ststistical significant difference between nurses' Knowledge and practice. Recommendations: Regular continuous educational program plan about chest trauma Encouraging nurses to attend national and international congresses, seminars, symposia, and workshops regularly about chest trauma.
\end{abstract}

\section{Keywords: performance, Chest Trauma, for \& Trauma Emergency Unit.}

\section{Introduction}

Chest trauma, the relatively sudden application of large physical forces to the chest, is a frequent cause of serious and fatal injury in present-day society. it has been estimated that $25 \%$ of fatalities due to motor vehicle accidents are due to chest trauma alone (Crayen, 2011) Chest injury can be either closed (blunt) or open (penetrating) injury and is further classified into primary injury and secondary injury. This classification is rather more useful while considering therapeutic and preventive strategies (Chowdhury et al., 2014).

Trauma nurses are involved with care of the trauma patient from arrival in the emergency department to follow-up in the trauma clinic. They respond to all Class 1 and Class 2 trauma activations and facilitate throughput of the patient from the trauma bay to diagnostic imaging and on to the intensive care unit. They perform procedures including chest tube insertion, central line insertion, arterial line insertion, and laceration repair, and act as a first assistant during trauma surgeries (Stewart, 2014).

The important role of the nurse in the technical administrative dimension is inherent to actions of caring and managing. Another relevant aspect is the systematization of the assistance to the patients according to the premises of advance trauma lift support (ATLS), which standardizes the health professionals' actions through the mnemonic airway, breathing, circulation, disability, exposer (ABCDE) approach. This approach makes it possible to identify and immediately treat the problems which put the patient at imminent risk of death, due to the lack of an initial diagnosis and limitation of data. Also point at the importance of the role of the nurse in articulating health professionals and in mobilizing resources for attention to the patient, this constituting a large part of their work in the ambit of management in the trauma room (Azevedo, Scarparo, \& Chaves, 2013).

The nursing management of these injuries requires a multidisciplinary approach with 3 primary components: pain management, respiratory therapy, and mobility. and physical therapy all play significant roles in the successful management of patients with chest wall injury(Dennis et al., 2017).The multiple trauma patients should be treated in rapidly and depending on the biomechanics of the trauma and the anatomic region that has been reached, the severity of the event causes great damage to their vital functions and it may cause, because of delayed care, irreversible sequels and even death (Carla, Alexandre, Silva, Oliveira, \& Barros, 2018).

Airway, breathing, and circulation should be checked in all the patients of chest trauma. Patency of the airway and the adequacy of the ventilator efforts

Vol , (7) No , (17) June, 2019 
should be evaluated with the assessment of the integrity of the chest and the circulatory status as pericardial tamponed can also cause signs and symptoms similar to tension pneumothorax. Upright positioning may be been call if there is no contraindication to it like the spinal injury. Penetrating wounds (also known as 'sucking chest wounds') require immediate coverage with an occlusive or pressure bandage made air-tight with clean plastic sheeting (Sharma \& Jindal, 2008).

\section{Significant}

Attended cases at Trauma Unit in the assuit University Hospitals were 19,869 in 2002 and increased up to 32,699 in 2009 . Out of the total cases in 8 years of study duration and According to the annual record of Assuit Hospital University 1032 of patients were admitted to the emergency trauma department during the year of 2016. And the numbers of the beds in the department are thousand forty beds Approximation (Record of trauma emergency unit Assuit hospital). The nurse is involved with the care of the trauma patient from arrival in the emergency department to follow-up in the trauma clinic.so the aim of the present study is nurses' performance regarding care of Chest Trauma patients at Trauma Emergency Unit.

\section{Aims of the study}

The aim of this study was to assess the nurses' performance regarding care of Chest Trauma patients at Trauma Emergency Unit.

\section{Hypotheses}

What is nurses' performance regarding care of chest trauma (nurses knowledge and practice).

\section{Subjects \& Methods \\ Study design}

The design of this study was a Descriptive design done to evaluate Trauma Emergency Nurse's performance with the care of Chest Trauma patients.

\section{Study Settings}

This study was conducted in the emergency trauma unit at Assuit University Hospital.

\section{Sample size}

All available nurses working in the emergency trauma unit at assuit university hospital (40) having more than one-year clinical experience and who provide direct care to the trauma patient.

\section{Study tools}

Tools were utilized to collect data in this study includes:-

\section{Tool I: nurses Knowledge Questione}

It was developed by the researcher based on the review of related literature to evaluate Trauma Emergency nurses knowledge related to care of patients with chest trauma and guided by ((Taylor's 2008; Morton 2014; Kowalak, 2010; Smeltzer et al., 2010).

It compromised two parts:

Part I: (demographic Data)

It included items related to nurses' personal data of studied nurses such as Code, age, sex, marital status, current occupation, the degree of qualification, years of experience, years of experience in caring of chest trauma, attendance of related training courses, date and time of courses.

Part II :( Nurses Knowledge sheet)

It included 6 items containing $\mathbf{5 2}$ questions, divided into two groups of questions a group of M.C.Q statements which included $\mathbf{4 4}$ questions classified as the following; anatomy \& physiology of respiratory system (21 questions), Information about definition of chest trauma (4 questions), mechanism and classification of chest trauma (5 questions) and causes and diagnosis of chest trauma (10 questions), management and life-threatening situation of chest trauma. (12 questions) and a group of open Questions statements which included (8 questions) regarding the nursing team Duties in patients with chest trauma. Nurses' responses were about what he knows about chest trauma calculated as the right answer took one score and the wrong answer took zero.

\section{Scoring system knowledge}

1. As regard nurse's knowledge, each correct answer was scored one and wrong answer was scored zero

- The total nurses answered score was summed up then converted into a percentage.

- Total nurses knowledge calculated as the following:

- All values $>65 \%$ were considered satisfactory.

- All value $<65 \%$ were considered unsatisfactory.

Tool II: Nurses Practice observation checklist.

It was developed by the researcher based related researcher, to assess trauma emergency nurses' practice in relation to the care of the patient with chest trauma. This tool consists of initial assessment and management regarding airway, breathing, circulation, disability, and exposure. It included five parts:

Part one: (Airway management)

Airway assessment and management includes (7 items containing 74 steps) divided into; manual airway maneuver ( 3 items containing 11 steps) (chin lift (4 steps), jaw thrust (3 steps), recovery position, (4 steps)), and Insertion of oral airway (10 steps), tracheal suction (20 steps), laryngeal mask (15 steps), and End tracheal tube intubation (18 steps).

Part two: (Breathing management)

Breathing Assessment and management includes: (3 items containing 41 steps) divided into; Administration of oxygen therapy (11 steps), bag-

Vol , (7) No, (17) June, 2019 
valve-mask (10 steps), and Chest tube insertion. (20 steps)

Part three: (Circulation management)

Circulation Assessment and management include: (3 items containing 41 steps) divided into; Assessment of shock (7 steps), Fluid resuscitation (23 steps), and Cardiopulmonary resuscitation (CPR) (11 steps).

Part four: (Level of conscious)

Disability assessment, to assess level conscious using (Alert - Voice - Pain - Unresponsive) (AVPU) (containing 8 steps)

Part five: (Injury Exposure check list)

This checklist to evolution sign injury (containing 8 steps)

It was a two-point licker scale of done correctly took two scores, done incorrectly took one score and not done took zero.

Scoring system Practice

As regard nurse's Practice, each step checked answer was scored done correctly took two scores, done incorrectly take one score and checked (not done) was scored zero.

- The total nurse's Practice score was summed up then converted to a percentage.

- Total nurses Performance s were calculated as the following:

- All values $>65 \%$ considered satisfactory Practice.

- All Values $<65 \%$ considered unsatisfactory Practice.

preparatory phase

An Official permission from the faculty of nursing to conduct the study was delivered to the hospital authorities (head department of emergency trauma unit) in Assuit university hospital and approval to conduct this study was obtained.

\section{Ethical considerations}

1- The research proposal was approved from the Ethical Committee in the faculty of nursing.

2- There is no risk for nurses during the application of research.

3- The study was followed by common ethical principles in clinical research.

4- Written consent was obtained from nurses that are participated in the study, after explaining the nature and purpose of the study.

5- Confidentiality and anonymity were assured.

6- Nurses had the right to refuse to participate and or withdraw from the study without any rational any time.

7- Nurse's privacy was considered during the collection of data.

- Content validity of the developer tools was done by 5 experts in the related fields. Three assistant professors of critical care nursing from Faculty of Nursing Assuit University. Two professors of critical care medicine from Assuit Faculty of Medicine.

Pilot study

Carried out before starting of data collection to test the feasibility and the clarity of the study tools on of the sample, the analysis of pilot study define the modification required in the tool used, and the necessary modification was done prior to data collection total of the nurses.

- The overall reliability of the tools was tested using $(\alpha)$ Cronbach's test for the pilot study results. It was found that the reliability of the tool one equal to 0.80 and the tool three equal to 0.84 , which was acceptable.

1- Implementation phase

- Data was collected at an emergency trauma unit at Assuit University Hospital

- Data were collected during the period from August 2017 to February 2018.

- The purpose of the study was to assess the nurses' performance regarding care of chest trauma patients at trauma emergency unit

- Permission for conducting the study was taken from the head of the nurse responsible for training after explaining the purpose, the time and the place of the study. Then she informed the head nurses of emergency trauma unit to obtain cooperation.

- Nurses were informed to participate in the study according to their need. Some nurses refused to participate throughout the study phases were not mandatory. Agreement on participation in the study was taken orally from nurses.

- Many copies of the questionnaire (Tool I), the observational checklist (Tool II), and evaluation of the nurses' practice related to care of patients with chest trauma.

- Interview questionnaire sheet: After taking the nursing oral agreement for voluntary participation in the study, each nursing was communicated personally by the researcher to fulfill the nursing assessment sheet.

- Filled after the purpose of the study was explained to the nurse prior to answering the question using (tool one)

- An observation checklist was carried out during nurses giving care for a patient with chest trauma the researcher observed by nursing performance in the morning and the afternoon shift (tool two)

2- Evaluating Phase

Each trauma nurse evaluated once by using Tool I (nurses Knowledge Tool) and Tool II (Practice Assessment Tool) 


\section{Statistical analysis:}

The raw data were coded and transformed into coding sheets. The results were checked. Then, the data were entered into SPSS system files (SPSS package version 18) using a personal computer. Output drafts were checked against the revised coded data for typing and spelling mistakes. Finally, the analysis and interpretation of data were conducted.

The following statistical measures were used:

- Mean percent score was calculated for both the knowledge and Performance of nursing care offered for patients with chest trauma among the studied nurses.
- Descriptive statistics including frequency, distribution, mean, and standard deviation were used to describe different characteristics.

- The data were tested for normality using the Anderson-Darling test and for homogeneity variances prior to further statistical analysis. Categorical variables were described by number and percent $(\mathrm{N}, \%)$, :-

$\mathrm{P}>0.05$ non-significant

$* \mathrm{P}<0.05$ significant

$* * \mathrm{P}<0.01$ moderate significant

$* * * \mathrm{P}<0.001$ highly significant.

\section{Results}

Table (1):- demographic characteristics of the studied nurses $(\mathrm{No}=40)$ :

\begin{tabular}{|c|c|c|}
\hline Items & No & $\%$ \\
\hline \multicolumn{3}{|l|}{ Age: } \\
\hline$<20$ & 2 & 5.0 \\
\hline $20-25$ & 17 & 42.5 \\
\hline $25-30$ & 19 & 47.5 \\
\hline$\geq 30$ & 2 & $\overline{5.0}$ \\
\hline Mean \pm SD (Range) & \multicolumn{2}{|c|}{ 24.9+3.6(19-35) } \\
\hline \multicolumn{3}{|l|}{ Gender: } \\
\hline Male & 9 & 22.5 \\
\hline Female & 31 & 77.5 \\
\hline \multicolumn{3}{|l|}{ Marital status } \\
\hline Single & 29 & 72.5 \\
\hline Married & 11 & 27.5 \\
\hline \multicolumn{3}{|l|}{ educational level } \\
\hline Nursing Diploma & 13 & 32.5 \\
\hline - Technical Institute of Nursing & 27 & 67.5 \\
\hline - B.Sc. Nurses & 0 & 00 \\
\hline \multicolumn{3}{|l|}{ Years of experience at the emergency department } \\
\hline$-<5$ years of experience & 17 & 42.5 \\
\hline $5-10$ years of experience- & 13 & 32.5 \\
\hline $10+$ years of experience- & 10 & 25.0 \\
\hline Mean \pm SD(range) & $5.5+3.5(1-12)$ & \\
\hline \multicolumn{3}{|l|}{ attendance of previous training chest trauma } \\
\hline Attended & 1 & 2.5 \\
\hline Not attended & 39 & 97.5 \\
\hline
\end{tabular}




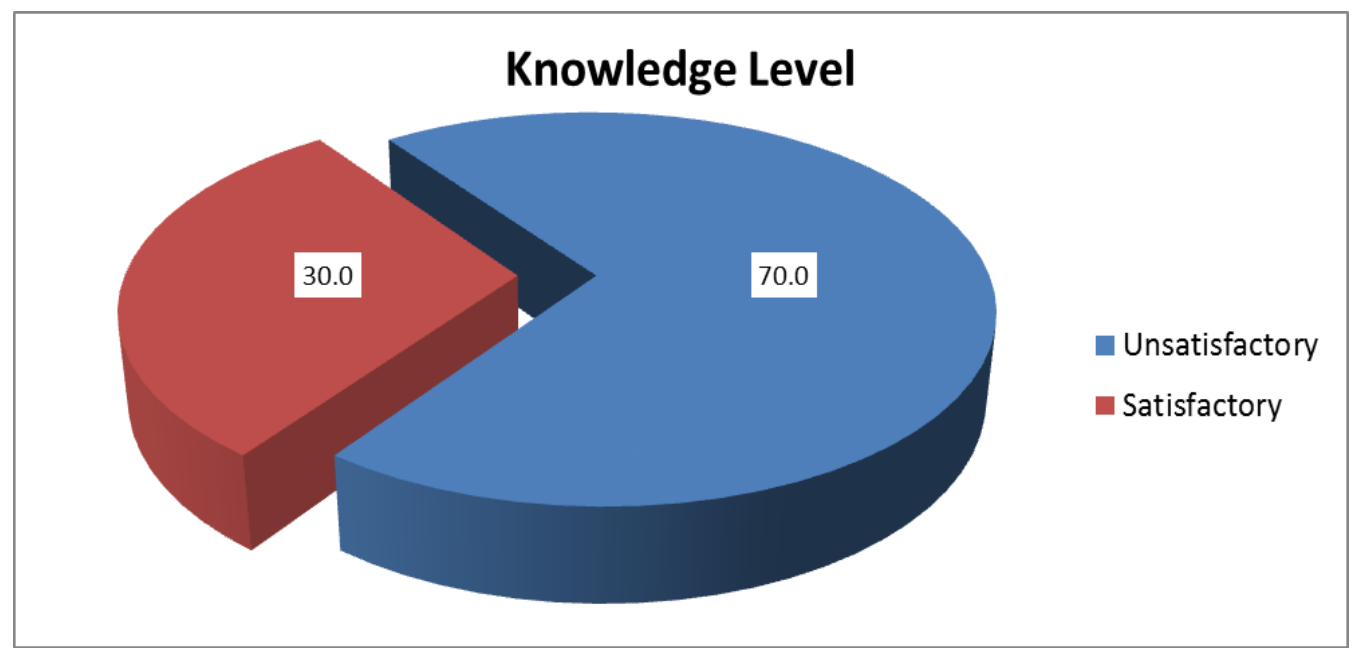

Figure (1): Level of satisfaction among Nurses' total scores of knowledge regarding chest trauma $(\mathrm{No}=40)$.

Table (2):- mean distribution of the Nurses' Knowledge chest trauma (No=40).

\begin{tabular}{|l|c|c|c|}
\hline items & Max Score & Range & Mean \pm SD \\
\hline \hline anatomy and physiologic of the respiratory system & 18 & $4-16$ & $10.95 \pm 2.88$ \\
\hline \hline Definition Chest Injuries & 4 & $0-4$ & $1.7 \pm 1.04$ \\
\hline \hline mechanisms and classification of chest injuries & 6 & $1-5$ & $3.53 \pm 1.18$ \\
\hline $\begin{array}{l}\text { causes and methods of diagnosis, signs, and symptoms } \\
\text { of chest injuries }\end{array}$ & 9 & $2-8$ & $4.85 \pm 1.63$ \\
\hline \hline Information on methods and treatment of chest injuries & 20 & $5-14$ & $9.88 \pm 2.44$ \\
\hline \hline Total Knowledge & $\mathbf{5 7}$ & $\mathbf{1 8 - 4 1}$ & $\mathbf{3 0 . 9} \pm \mathbf{6 . 1 4}$ \\
\hline
\end{tabular}

\section{Total Practice Level}

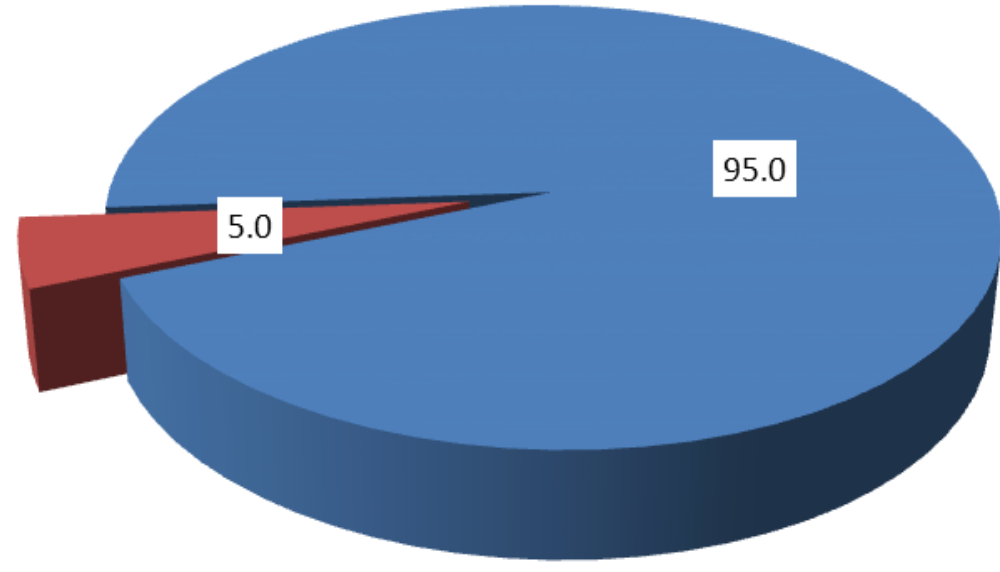

Unsatisfactory

Satisfactory

FIGURE (2): Frequency distribution of the Nurses' in relation to the assessment of Nurses' level of practical $(\mathrm{No}=40)$. 
Table (3): Mean distribution of the Nurses' practice related chest trauma (No=40)

\begin{tabular}{|c|c|c|c|}
\hline Items & Score & Range & $\mathrm{M} \pm \mathrm{SD}$ \\
\hline$\overline{\text { airway }}$ & 148 & $61-85$ & $66.3 \pm 4$ \\
\hline Manual airway & 22 & $10-14$ & $10.1 \pm 0.63$ \\
\hline chin lift & 8 & $3-4$ & $3.03 \pm 0.16$ \\
\hline Jaw thrust & 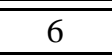 & $3-5$ & $3.05 \pm 0.32$ \\
\hline recovery position & 8 & $4-5$ & $4.03 \pm 0.16$ \\
\hline oral airway insertion & 20 & $10-14$ & $10.75 \pm 0.71$ \\
\hline tracheal suction & 40 & $14-26$ & $17.9 \pm 1.91$ \\
\hline Intubating Laryngeal Mask Airway & 30 & $14-15$ & $14.05 \pm 0.22$ \\
\hline 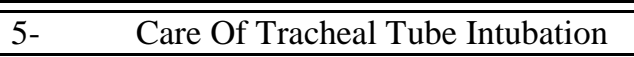 & $\overline{36}$ & $\overline{11-16}$ & $13.5 \pm 2.53$ \\
\hline Breathing & 92 & $35-66$ & $48.8 \pm 7.4$ \\
\hline Oxygen therapy & 32 & $13-22$ & $16.48 \pm 2.74$ \\
\hline Suction & 20 & $5-16$ & $10.15 \pm 3.08$ \\
\hline Chest tube & 40 & $10-36$ & $22.18 \pm 5.83$ \\
\hline$\overline{\text { Circulation }}$ & 112 & $63-82$ & $73.33 \pm 4.03$ \\
\hline Shock & 18 & $\overline{10-13}$ & $10.78 \pm 0.66$ \\
\hline Fluid & 72 & $47-59$ & $53.68 \pm 2.42$ \\
\hline CPR & 22 & 3-14 & $8.88 \pm 2.17$ \\
\hline Technique exposer & 26 & 14-18 & $14.2 \pm 0.88$ \\
\hline Level of conscious(A_V_P_U) & 8 & $3-3$ & $3 \pm 0$ \\
\hline total Performance & 386 & 186-242 & $205.63 \pm 11.77$ \\
\hline
\end{tabular}

Table (4): Relationship between Nurses' Total Knowledge Level According to their demographic data $(n=40)$.

\begin{tabular}{|c|c|c|c|c|c|}
\hline \multirow{3}{*}{ Variable } & \multicolumn{5}{|c|}{ Total Knowledge Level } \\
\hline & \multicolumn{2}{|c|}{ Unsatisfactory } & \multicolumn{2}{|c|}{ Satisfactory } & \multirow{2}{*}{ P. value } \\
\hline & No & $\%$ & $\overline{\text { No }}$ & $\overline{\%}$ & \\
\hline \multicolumn{5}{|l|}{$\overline{\text { Age: }}$} & \multirow{5}{*}{$0.050 *$} \\
\hline$<20$ & 2 & 7.1 & 0 & 0.0 & \\
\hline $20-25$ & 8 & 28.6 & 9 & 75.0 & \\
\hline $25-30$ & 16 & 57.1 & 3 & 25.0 & \\
\hline$\geq 30$ & 2 & 7.1 & 0 & 0.0 & \\
\hline \multicolumn{5}{|l|}{ Gender: } & \multirow{3}{*}{0.160} \\
\hline Male & 8 & 28.6 & 1 & 8.3 & \\
\hline Female & 20 & 71.4 & 11 & 91.7 & \\
\hline \multicolumn{5}{|l|}{ Marital status } & \multirow{3}{*}{0.189} \\
\hline Single & 22 & 78.6 & 7 & 58.3 & \\
\hline Married & 6 & 21.4 & 5 & 41.7 & \\
\hline \multicolumn{5}{|l|}{ Nurses' qualification } & \\
\hline Nursing Diploma & 7 & 25.0 & 6 & 50.0 & \\
\hline
\end{tabular}




\begin{tabular}{|c|c|c|c|c|c|}
\hline \multirow{3}{*}{ Variable } & \multicolumn{5}{|c|}{ Total Knowledge Level } \\
\hline & \multicolumn{2}{|c|}{ Unsatisfactory } & \multicolumn{2}{|c|}{ Satisfactory } & \multirow{2}{*}{ P. value } \\
\hline & No & $\%$ & No & $\%$ & \\
\hline Technical Institute of Nursing & 21 & 75.0 & 6 & 50.0 & \multirow[b]{2}{*}{0.203} \\
\hline B.Sc. Nurses & - & - & - & - & \\
\hline \multicolumn{5}{|c|}{ Years of experience at the emergency department } & \multirow[b]{4}{*}{0.066} \\
\hline - $<5$ years of experience & 9 & 32.1 & 8 & 66.7 & \\
\hline$-5-10$ years of experience- & 12 & 42.9 & 1 & 8.3 & \\
\hline$-10+$ years of experience- & 7 & 25.0 & 3 & 25.0 & \\
\hline \multicolumn{5}{|c|}{ attendance of previous training course chest trauma } & \multirow{3}{*}{0.122} \\
\hline Attended & 0 & 0.0 & 1 & 8.3 & \\
\hline Not attended & 28 & 100.0 & 11 & 91.7 & \\
\hline
\end{tabular}

- Chi-square test, * Significant difference

$(N . B)$ :- N.s $(p>0.05)$ no significance

$* p<0.05$ significance

$* * p<0.001$ moderate significance $* * * p<0.0001$ high significance

Table (5): Relationship between Nurses' practice According to their demographic data (n=40).

\begin{tabular}{|c|c|c|c|c|c|}
\hline \multirow{3}{*}{ Items } & \multicolumn{5}{|c|}{ Practice Level } \\
\hline & \multicolumn{2}{|c|}{ Unsatisfactory } & \multicolumn{2}{|c|}{ Satisfactory } & \multirow{2}{*}{$\begin{array}{c}P . \\
\text { value }\end{array}$} \\
\hline & No & $\%$ & No & $\%$ & \\
\hline \multicolumn{5}{|l|}{ Age } & \multirow{5}{*}{0.416} \\
\hline Less than 20 & 2 & 5.3 & 0 & 0.0 & \\
\hline $20-25$ & 15 & 39.5 & 2 & 100.0 & \\
\hline $25-30$ & 19 & 50.0 & 0 & 0.0 & \\
\hline More than 30 & 2 & 5.3 & 0 & 0.0 & \\
\hline \multicolumn{5}{|l|}{ Gender: } & \multirow{3}{*}{0.434} \\
\hline Male & 9 & 23.7 & 0 & 0.0 & \\
\hline Female & 29 & 76.3 & 2 & 100.0 & \\
\hline \multicolumn{5}{|l|}{ Marital status } & \multirow{3}{*}{0.465} \\
\hline Single & 28 & 73.7 & 1 & 50.0 & \\
\hline Married & 10 & 26.3 & 1 & 50.0 & \\
\hline \multicolumn{5}{|l|}{ Nurses' qualification } & \multirow{4}{*}{0.822} \\
\hline Nursing Diploma & 12 & 31.6 & 1 & 50.0 & \\
\hline Technical Institute of Nursing & 26 & 68.4 & 1 & 50.0 & \\
\hline B.Sc. Nurses & - & - & - & - & \\
\hline \multicolumn{5}{|c|}{ Years of experience at the emergency department } & \multirow[b]{4}{*}{0.686} \\
\hline$<5$ years of experience & 16 & 42.1 & 1 & 50.0 & \\
\hline $5-10$ years of experience & 12 & 31.6 & 1 & 50.0 & \\
\hline $10+$ years of experience- & 10 & 26.3 & 0 & 0.0 & \\
\hline
\end{tabular}




\begin{tabular}{|c|c|c|c|c|c|}
\hline \multirow{3}{*}{ Items } & \multicolumn{5}{|c|}{ Practice Level } \\
\hline & \multicolumn{2}{|c|}{ Unsatisfactory } & \multicolumn{2}{|c|}{ Satisfactory } & \multirow{2}{*}{$\begin{array}{c}P . \\
\text { value }\end{array}$} \\
\hline & No & $\%$ & No & $\%$ & \\
\hline \multicolumn{5}{|c|}{ attendance of previous training course chest trauma } & \multirow{3}{*}{0.816} \\
\hline Attended & 1 & 2.6 & 0 & 0.0 & \\
\hline Not attended & 37 & 97.4 & 2 & 100.0 & \\
\hline
\end{tabular}

- Chi-square test, * Significant difference at p. value $<0.05$ $(N . B):-N . s(p>0.05)$ no significance $* p<0.05$ significance $* * p<0.001$ moderate significance $* * * p<0.0001$ high significance

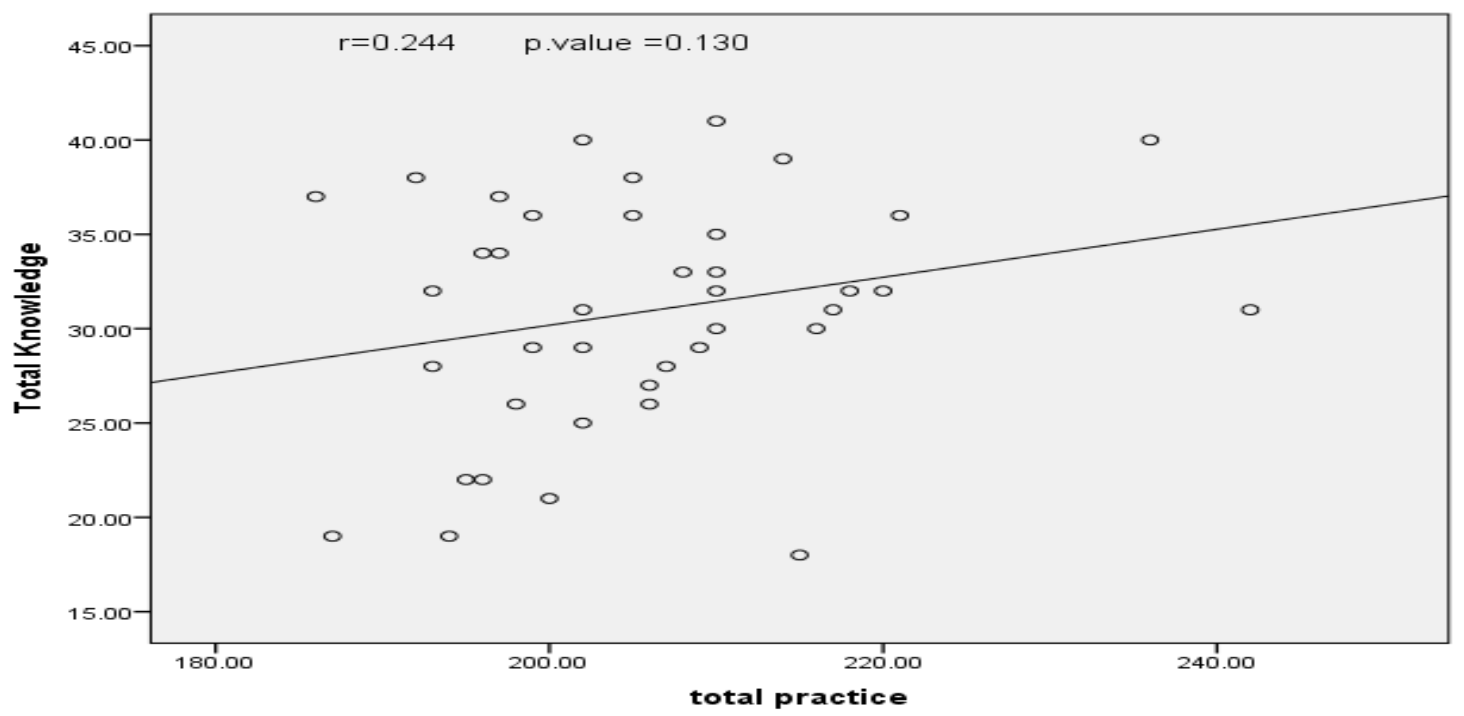

Figure (3): correlation between nurses' knowledge and practice regarding care patients of Chest Trauma $(\mathrm{No}=\mathbf{4 0})$.

Table (1): Shows the Socio-demographic data of studied nurses. It was found that $62 \%$ of them were in the age group from 25 to 30 years, 77,5\% were female and $72,5 \%$ were single. About their educational level $67,5 \%$ of the Technical Institute of Nursing, $32.5 \%$ of the nurses held a Nursing Diploma. More than that, 42,5\% nurses had work experience in nursing less than 5 years, $32 \%$ of them had from 5-10 years' experience and $25 \%$ of them had working experience more than 10.anther $42,5 \%$ nurses had work experience in nursing less than 5 years, $32 \%$ of them had from 5-10 years' experience and $25 \%$ of them had working experience more than 10 . In relation to their previous training on course chest trauma, the table reveals that $97,5 \%$ of them were not receiving any previous course chest trauma training.

Figure (1): This figure shows that the majority of the nurses $(70 \%)$ had unsatisfactory. Level of nurses
Knowledge regards total score, while (30\%) satisfactory Level total scores about chest trauma.

Table (2): This table show Frequency distribution of the Nurses' Knowledge emergency department trauma: - it was apparent from this table $\mathrm{M} \pm \mathrm{SD}$ mean score of the items Nurses' Knowledge (anatomy and physiologic, Definition Chest trauma, mechanisms and classification, causes and signs and symptoms, and treatment of chest injuries) were $(10.95 \pm 2.88, \quad 1.7 \pm 1.04, \quad 3.53 \pm 1.18$, $4.85 \pm 1.639 .88 \pm 2.44)$ respectively It was found also from this table that total $\mathrm{M} \pm \mathrm{SD}$ of Nurses' Knowledge was (30.9 \pm 6.14$)$

Figure (2): This figure shows that the majority of the Nurses' (95\%) had unsatisfactory. Level of nurse's practice regards total score, while $(5.0 \%)$ satisfactory Level total scores about chest trauma.

Table (3): This table show Frequency distribution of the Nurses' practice emergency trauma: - it was 
apparent from this table $\mathrm{M} \pm \mathrm{SD}$ mean score of the items Nurses' practical (airway, Manual airway, a chin lift, b. Jaw thrust, c. recovery position. Oral airway insertion, tracheal suction, Intubating Laryngeal Mask Airway, Care Of Tracheal Tube Intubation) were $(10.1 \pm 0.63,3.03 \pm 0.16,3.05 \pm 0.32$, $4.03 \pm 0.16, \quad 10.75 \pm 0.71, \quad 17.9 \pm 1.91, \quad 14.05 \pm 0.22$, 13.5 \pm 2.53 ) (Breathing. Oxygen therapy, Suction, Chest tube) were $(48.8 \pm 7.4,16.48 \pm 2.74,10.15 \pm 3.08$, 22.18 \pm 5.83 ) (Circulation, shock, fluid, CPR) were $(73.33 \pm 4.03, \quad 10.78 \pm 0.66, \quad 53.68 \pm 2.42, \quad 8.88 \pm 2.17)$ (Technique, Level of conscious) were (14.2 \pm 0.88 , $3 \pm 0$ ) respectively It was found also from this table that total $\mathrm{M} \pm \mathrm{SD}$ of Nurses' practice was (205.63 \pm 11.77$)$

Table (4): Presents the relationship between total score of nurses' knowledge and demographic variables. The table revealed that, the highest mean scores of nurses' knowledge in relation to age group 25-30 years were $57.1 \%$ Unsatisfactory compared with $75.0 \%$ satisfactory to age group $20-25$ years old present statistical significant difference between age and nurses' knowledge $\left(\mathrm{p}<0.050^{*}\right)$, while there was no relationship between the total score of nurses' knowledge and the other socio-demographic variables .

Table (5): Presents the relationship between total score of nurses' knowledge and demographic variables. The table revealed that, the highest mean scores of nurses' knowledge in while there was no relationship between the total score of nurses' knowledge and the other socio-demographic variables

Figure (3): Correlation between nurses' knowledge and practice regarding chest trauma this figure illustrates that: there was no a ststistical significant difference between nurses' Knowledge and practice. $(\mathbf{r}=\mathbf{0 . 2 4 4} \quad \mathbf{p}=\mathbf{0 . 1 3 0})$

\section{Discussion}

Thoracic trauma is one of the major heavy loads in poly-traumatized patients. Traumatic injury is even the most common cause of death. Thoracic injuries are responsible for twenty five percent of deaths (Milisavljević et al., 2016) Currently, injury in India is a big cause of years of productive life lost and the leading cause of death for those under Thirty-five years old. This national injury heavy loads is growing and the ongoing rise in the trauma burden is mostly in the form of road traffic crashes(Mitra et al., 2017)(Chowdhry \& Rathinam, 2017).

The current study was aimed to assess the nurses' performance regarding care of Chest Trauma patients at Trauma Emergency Unit
The results of the present study showed that more than half of the nurses were in the age group from twenty five to thirty years, Female, and Single, more than half of the nurses were in the qualification of Technical Institute of Nursing This result may be due to the old belief that nursing is profession to female so most of nurses in Egypt are females. This results is in agreement with (Diab \& Mabrouk, 2015). Most of the nurses their age ranged from twenty five to Twenty-nine years, and working as staff nurses at specialty hospital setting, as regard the educational level; Most of the nurses had diploma of nursing, their experiences below five years, and difficult chance to attend training courses about the disasters, and obtained information on disasters through different mass media. Also, this finding is in accordance with (Ibrahim, 2016) Slightly more than half of them were aged less than thirteen years. Also, more than half of the studied nurses had a technical education. And half of them their years of experience at the emergency department low fifth. also agree with a study done by (Elfaki et al., 2016) More than that, about half of them had less than teen years' experience. And the agreement with a study done by(Ibrahim, 2016) According to their years of experience it was found that less than two-thirds of them had experienced less than five years.

The presant study was disagree with a study done by (Elfaki et al., 2016) The study was included fifty nurses, their age range from twenty one to Forty five years. The present study the findings revealed that all nurses had not attended any previous training courses about the chest trauma. This went in the line with (Bedier, et al., 2016) the findings of the present study indicated that the majority of studied nurses did not have any undergraduate training courses about chest trauma care as they graduated from secondary nursing school and about half of them had less than teen years' experience. Also, they did not attend any postgraduate training program related to chest trauma.

Also agreement with (Ibrahim, 2016) majority of nurses had not attended educational lectures or workshops concerning chest trauma management. also agreement with (Bedier et al., 2016) they did not attend any postgraduate training program related to chest trauma or chest tube. While only one third of them attended training program related to infection control.

As well, the great majority in the current study had unsatisfactory knowledge level about chest trauma in all items. This is an expected finding. Due to lack of preparation during the basic education, lack of desire of nurses to acquire new knowledge, overload in the working situation and lack of continuing education

Vol , (7) No , (17) June, 2019 
courses related to the care of the patient with chest trauma. All nurses with a diploma degree and Technical Institute of Nursing, with the not specific qualification about chest trauma.

This result is congruent with(Yousef, Mohamed, Ali, \& Ali, 2018) In Egypt, nursing is a female occupation, and this gives a reason why the entire study sample was female. The unsatisfactory level of nurses knowledge in the initial assessment might be due to the inadequate educational preparation level and lack of in-service training, This result is congruent with (Carla, et al., 2018) A Brazilian study, with One hundred and forty-four nurses, emphasizes that nurses recognize that continuous education is an important tool that has a positive influence in the nursing care in a way that they could enhance their knowledge.

The present study agreement with (Rasouli, et al., 2016)Within limitation of his study the results show that majority of participants had low level of knowledge about trauma and taking care of traumatic patients in both male and female staff and in both the results of the study represented that there was no significant difference in their level of knowledge in regard to their demographic characteristics. According to the epidemiology of trauma, Also, these results are in agreement with (Hatata et al., 2018) (Hatata et al., 2013) The total knowledge score and the score of all its items increased significantly immediate post-intervention. This reflects the lack of knowledge among nursing about the chest trauma and falls.

This study Agreement with (Curtis, Lien, Chan, Grove, \& Morris, 2002) their analysis of the impact of the trauma nurse practitioner on the quality of care for trauma patients in a large US institution found that the introduction of a trauma nurse practitioner reduced the time of surgical house-staff activities such as teaching patients and completing discharge. Also, this study agreement by(Goldstein et al., 2017) This may be due to nurses' lack of confidence in their ability to differentiate between mild, moderate and severe pain, the pain severity discriminator not actually changing the triage category, or, sadly, staff becoming immune to patients' complaints of pain (pain is one of the most common reasons for presentation.

Also, these results are in agreement with (Feizi Nazarloo et al., 2017) In the present study, most subjects had a poor awareness status, regarding the field of protection of forensic evidence. In a study conducted in emergency wards of the city of Durban, South Africa, most nurses had problems with the protection of forensic evidence and had not experienced any training in the protection chain, moreover, disagreement by (Elfaki et al., 2016) Nurses had good knowledge about indications and time for chest tube removal and average knowledge about the basic principles of chest derange system function, complications, action when trauma leakage and dislodge and had poor knowledge to do action when the traumas displacement.

Moreover agreement with (Curtis, et al., 2002) These injury statistics could have significant impact on medico legal issues, representation, longer admissions and patient satisfaction. They raise the possibility that patients may have been going home with undetected injuries and taking longer to get back to work and return to their previous functional status. Furthermore, unrecognized injuries may not only have an adverse impact on patient outcomes, but they can also compromise the credibility of both the clinicians and the institution.

As revealed from the current study, the majority of the nurses were having unsatisfactory level regarding show level Nurses' practical about chest trauma. Outcomes are dependent this is may be attributed to interpreting the reasons for nurses' inadequate practice to an absence of incorporation chest trauma course in a nursing curriculum of the taught nursing program. Other relevant factors included lack of inservice training program, lack of the availability of qualified nurses, and guidelines in nurses' work areas. Moreover, another possible explanation for that phenomenon is the lack of funding aimed at organizing nurses' regular workshops. Another factor for lack of nurses' practice in the current study was nurses' workload which made the delay of nurses' abilities and motives to acquire and update their knowledge and practice. However, nurses' understanding of practice chest trauma could even save the patient's life in time. This result is congruent with (Garvey et al., 2016) A review of literature revealed a lack of research on nursing-focused trauma education courses.

Agreement by (Rasouli et al., 2016) that methods of nursing education can be useful in improving practice skills and relationships of nurses in an emergency unit. The generic approach (the ABC approach) should be taught at an excellent level to be applicable in supporting injured patients. this study disagreement with (Curtis et al., 2012) Errors in trauma management contribute significantly to preventable or potentially preventable morbidity and mortality. Implementing and maintaining principles of standardizing trauma care is vital to optimizing patient recovery and emergency nurses are to this process.

Concerning correlation between Nurses', knowledge and practice and their demographic characteristics 
revealed that there present statistical significant difference only age. This study agreement by(Abd Alsemia Elewa \& Abd Elshahed Ahmed Elkattan, 2017) in the present study, nearly half of them their age ranged between $30-<40$ years, this result may be due to that this age group is the common age of nurses who give care for the patient's chest trauma. This study agreement by (El-hay, Ahmed, \& Sharshor, 2018) Also the study result revealed that there was statistical significant positive correlation among nurses' knowledge and practice and their socio-demographic characteristic included; age, gender, level of education, and years of experience Also, agreement with(Al-mawsheki, Ibrahim, \& Taha, 2016) The present study showed a significant difference between nurse's knowledge scores and their age. This may be due to the studied nurses were spent much time for caring for these patients. Disagreement by (El-hay et al., 2018) Also the study result revealed that there was statistical significant positive correlation among nurses' knowledge and practice and their socio-demographic characteristic included; age, gender, level of education, and years of experience

Concerning the relationship between knowledge and practice, the present study revealed that there was no a ststistical significant difference between nurses Knowledge and practice. $(\mathbf{r}=\mathbf{0 . 2 4 4} \mathbf{p = 0 . 1 3 0})$ This is interpreted that reasons for lack of knowledge and practice about chest trauma due to an absence of preemployment orientation programs and in-service training courses. These results were supported by (Abd Alsemia Elewa \& Abd Elshahed Ahmed Elkattan, 2017) The present study finding revealed that, there was a statistically significant correlation between the total score of nurses' knowledge and practice, which indicates the positive relation between knowledge and practice. This result refers to the level of practice influenced by the level of knowledge. our finding contradicted with (Khalil, 2018) who stated that many nurses were aware of their inadequate knowledge and related it to inadequate care practices.

Conclusion the majority of the nurses was having an unsatisfactory level regarding nurses' knowledge and practice. There was no a ststistical significant difference between nurses' Knowledge and practice.

The study recommended that

1- Upgrading nurses' knowledge and Performance about caring for patients with chest trauma through:

2- Encouraging nurses to attend national and international congresses, seminars, symposia, and workshops regularly about chest trauma \& care of patients with the chest trauma.
3- Regular continuous educational program plan about chest trauma\& its management should designed for nurses working in the emergency at least every six months for enhancing nurses' knowledge and practice to achieve the high quality of care.

4- Nurses involved in patient care should have a valid the Advanced Trauma Life Support (ATLS) program care certification and renew it regularly at least every two years.

\section{Acknowledgements}

We express great thanks to all nurses who kindly participate in this study for their cooperation.

\section{References}

1. Abd Alsemia Elewa, A., \& Abd Elshahed Ahmed Elkattan, B., (2017): Effect of an Educational Program on Improving Quality of Nursing Care of Patients with Thalassemia Major as Regards Blood Transfusion. American Journal of Nursing Research, 5(1), 13-21.

2. Al-mawsheki, E., Ibrahim, M., \& Taha, N., (2016): Nurses $\hat{a} €^{\mathrm{TM}}$ Knowledge and Practice Regarding Care for the Patients during Hemodialysis, 84(1), 1135-1141.

3. Azevedo, A., Scarparo, A., \& Chaves, L., (2013): Nurses' care and management actions in emergency trauma cases. Invest Educ Enferm, 31(1), 36-43.

4. Bedier, N., Bakr Abo EL-Ata, A., \& Mohammed Ibrahim, N., (2016): international journal of nursing didactics Impact of an Educational Program on Nurses' Knowledge Related to Care of Patients with Chest Tube. International Journal of Nursing Didactics, 6.

5. Bouzat, P., Raux, M., David, J., Tazarourte, K., Galinski, M., Desmettre, T., Le, M., (2017): Chest trauma: First 48 hours management. Anaesthesia Critical Care and Pain Medicine, 36(2), 135-145.

6. Carla, A., Alexandre, S., Silva, J., Oliveira, W., \& Barros, J., De. (2018): Nursing Conduct for Major Trauma Patients : Initial Care Provided at the Red Nursing Conduct for Major Trauma Patients : Initial Care Provided at the Red Zone of an Emergency Department, (April).

7. Chowdhry, T., \& Rathinam, S., (2017): Penetrating injuries of the chest. Surgery(UnitedKingdom),35(5),255-261.

8. Chowdhury, T., Kowalski, S., Arabi, Y., \& Dash, H., (2014): Pre-hospital and initial management of head injury patients: An update. Saudi Journal of Anaesthesia, 8(1), 114.

9. Curtis, K., Caldwell, E., Delprado, A., \& Munroe, B., (2012): Traumatic injury in Australia and New Zealand. Australasian Emergency Nursing Journal, 15(1), 45-54. 
10. Curtis, K., Lien, D., Chan, A., Grove, P., \& Morris, R., (2002): The impact of trauma case management on patient outcomes. The Journal of Trauma, 53(3), 477-482.

11. Dennis, B., Bellister, S., Guillamondegui, O., Puapong, D., \& Tuggle, D., (2017): Thoracic Trauma. Surgical Clinics of North America, 97(5), 1047-1064.

12. Diab, G., \& Mabrouk, S., (2015): The effect of guidance booklet on knowledge and attitudes of nurses regarding disaster preparedness at hospitals. Journal of Nursing Education and Practice, 5(9), 17-31.

13. El-hay, S., Ahmed, R., \& Sharshor, S., (2018): Effect of Educational Guidelines on Nurses Performance Regarding management of Patients undergoing Bone marrow Transplantation, 7(1), 69-80.

14. Elfaki, B., Mustafa, H., \& Hassan Ahmed, A., (2016): Nurses' knowledge and Practice regard Care of Patient with Chest Drains in Sudan Heart Center, Khartoum, Sudan. IOSR Journal of Nursing and Health Science, 5, 2320-1940.

15. Feizi Nazarloo, L., Sedghi Sabet, M., JaafarAghaii, F., Kazem Nezhad Leyli, E., Rahbar Taromsari, M., \& Jolly, A., (2017): Emergency Department Nurses's Knowledge about Forensic Nursing. Journal of Holistic NursingAndMidwifery,27(3),27-36.

16. Garvey, P., Liddil, J., Eley, S., \& Winfield, S., (2016): Trauma tactics: Rethinking Trauma education for professional nurses. Journal of Trauma Nursing, 23(4), 210-214.

17. Kowalak J., (2010): Lippincott Of Manual Nursing Procedures. $\quad\left(9^{\text {th }}\right.$ ed). Wolters Kluwer Health/Lippincott Williams \& Wilkins; P.p. 277278.

18. Hatata, E., Soliman, S., Refaat, R., \& Professor, A., (2013): Prevention of recurrent falls in elderly: a pre-post intervention study in a rural community, Egypt. International Journal of Collaborative Research on Internal Medicine \& Public Health, 5(4), 187-198. Retrieved from

19. Hatata, E., Soliman, S., Refaat, R., Professor, A., Dnp, D., Dnp, D., Winfield, S., (2018): PostTraumatic Pulmonary Pseudocyst following Blunt Chest Trauma; a Case Report. Journal of Thoracic Disease, 4(1), 1-13.

20. Ibrahim, R., (2016): Impact of an Educational Program on Knowledge and Practices of Nurses about Caring of Patient with Chest Tube. IOSR Journal of Nursing and Health Science, 5(6), 2320 1940.

21. Khalil, N., (2018): Critical care nurses â€ $€^{\mathrm{TM}}$ knowledge and practice regarding life-threatening ventricular dysrhythmias, 15, 747-753.

22. Mahran, D., Farouk, O., Qayed, M., \& Berraud, A., (2013): Hospitalized injuries and deaths in a trauma unit in upper Egypt. International Journal of Critical Illness and Injury Science, 3(4), 235.

23. Milisavljević, S., Spasić, M., Arsenijević, M., Sharp, C., Hons, B., Dacvecc, M., Access, O. (2016): The Poly-Traumatized Patient with Fractures. Journal of Trauma and Acute Care Surgery, 7(6), 1-437.

24. Mitra, B., Mathew, J., Gupta, A., Cameron, P., O'Reilly, G., Soni, K., Fitzgerald, M., (2017): Protocol for a prospective observational study to improve prehospital notification of injured patients presenting to trauma centres in India. BMJ Open, 7(7).

25. Morton P., \& Fontaine D., (2014): Critical care nursing: a holistic approach $\left(10^{\text {th }}\right.$ ed). Lippincott Williams \& Wilkins; P.p. 516-520.

26. Rasouli, A. S., Alizadeh, S., Vahdati, S. S., Jafarabadi, M., \& Pouraghaei, M., (2016): Investigating nursing students' level of knowledge in caring for trauma patients. Acta Medica Mediterranea, 32(Speciallssue2), 1062-1066.

27. Sharma, A., \& Jindal, P., (2008): Principles of diagnosis and management of traumatic pneumothorax. Journal of Emergencies, Trauma and Shock, 1(1), 34.

28. Smeltzer S., Bare B., Hinkle J., \& Cheever K., (2010): Brunner \& Suddarth's Text Book Of Medical-Surgical Nursing. $\left(12^{\text {th }}\right.$ ed).

29. Stewart, D., (2014): Blunt Chest Trauma. Journal of Trauma Nursing, 21(6), 282-284.

30. Taylor C., Lemone P., Lynn P., \& Lillis C., (2008): Fundamentals of nursing the art and science of nursing care. Wolters Kluwer Health/Lippincott Williams \& Wilkins; P. 1633.

31. Yousef, A., Mohamed, W., Ali, F., \& Ali, E., (2018): Effect of Nursing Education Guidelines about High Alert Medications on Critical Care Nurses Knowledge and Practices ., 7(1), 47-54. 